\title{
PROPOSIÇÕES DA OCDE PARA AMÉRICA LATINA: O PISA COMO INSTRUMENTO DE PADRONIZAÇÃO DA EDUCAÇÃO
}

\author{
PROPOSICIONES DE LA OCDE PARA AMÉRICA LATINA: EL PISA COMO \\ INSTRUMENTO DE PADRONIZACIÓN DE LA EDUCACIÓN
}

\author{
OECD PROPOSITIONS FOR LATIN AMERICA: PISA AS A STANDARDIZATION \\ INSTRUMENT FOR EDUCATION
}

\author{
Rodrigo da Silva PEREIRA ${ }^{1}$
}

\begin{abstract}
RESUMO: Este artigo tem como objetivo analisar as proposições educacionais da Organização para Cooperação e Desenvolvimento Econômico (OCDE) para a região latino-americana. Para isso analisa documentos que apresentam propostas aos países da região. Parte-se da compreensão que, a partir dos resultados do Programa Internacional de Avaliação de Alunos (Pisa), o Organismo Internacional pressiona os países a adotarem uma concepção que tem como seu epicentro a política de competências e habilidades para atender as demandas do mercado de trabalho no mundo globalizado. Aponta contradições nas proposições que, na aparência defendem a educação pública, mas, em essência, intentam padronizar os sistemas. Conclui que o viés comparativo a fim de padronização caminha na contramão das finalidades públicas e sociais da educação.
\end{abstract}

PALAVRAS CHAVES: Política educacional. OCDE. PISA. América Latina.

RESUMEN: Este artículo tiene como objetivo analizar las proposiciones educativas de la Organización para la Cooperación y el Desarrollo Económico (OCDE) para la región latinoamericana. Para ello analiza documentos que presentan propuestas a los países de la región. Se parte de la comprensión que, a partir de los resultados del Programa Internacional de Evaluación de Alumnos (Pisa), el Organismo Internacional presiona a los países a adoptar una concepción que tiene como su epicentro la política de competencias y habilidades para atender las demandas del mercado de trabajo en el mundo globalizado. Aun contradice las proposiciones que, en apariencia defienden la educación pública pero, en esencia, intentan estandarizar los sistemas. Concluye que el sesgo comparativo a fin de estandarización camina en contra de las finalidades públicas y sociales de la educación.

PALABRAS CLAVES: Política educativa. OCDE. PISA. América Latina.

ABSTRACT: This article aims to analyze the educational propositions of the Organization for Economic Cooperation and Development (OECD) for the Latin American region. For this, it analyzes documents that present proposals to the countries of the region. It is based on the

${ }^{1}$ Universidade Federal da Bahia (UFBA), Salvador - BA - Brasil. Professor adjunto da Faculdade de Educação, atuando na graduação e no Programa de Pós-Graduação em Educação. Membro da Linha de Pesquisas em Políticas e Gestão da Educação/FACED-UFBA. ORCID: https://orcid.org/0000-0003-0371-3789. Email: rodrigosilvapereira@ufba.br 
understanding that, based on the results of the International Program for Student Assessment (Pisa), the International Organization urges countries to adopt a concept that has as its epicenter the policy of skills and abilities to meet the demands of the market of work in the globalized world. It points out contradictions in the propositions that, in appearance, defend public education, but, in essence, attempt to standardize systems. It concludes that the comparative bias towards standardization is contrary to public and social purposes of education.

KEYWORDS: Educational Policy. OECD. PISA. Latin America.

\section{Introdução}

Desde os anos 2000 a Organização para Cooperação e Desenvolvimento Econômico (OCDE) busca verificar a situação dos sistemas educacionais de seus países membros e de outras nações que se dispõem a participar do Programa Internacional de Avaliação dos Alunos (Pisa). O Pisa verifica o desempenho acadêmico em três áreas do conhecimento, Leitura, Matemática e Ciências, por meio do conceito de letramento científico. De caráter tri-anual, as provas são organizadas a fim de colher informações do estágio da aprendizagem de alunos com 15 anos de idade, desde que estes estejam cursando a partir do $7^{\circ}$ ano da educação primária.

Além dos 35 países membros da OCDE, o Pisa conta com uma participação mais ampla de nações. Na edição de 2015 participaram outras 38 economias, totalizando a participação de 70 países e 3 economias "isoladas" (Hong Kong, Macao e Taipei). Seu alcance demonstra a capacidade de articulação e difusão do programa ao redor do mundo, uma vez que não há outra experiência tão abrangente como a do Pisa em processos de verificação em larga escala de sistemas educativos.

De acordo com a OCDE, os resultados do programa proporcionam aos países a possibilidade de aferir se os jovens naquela faixa etária adquiriram ou não as competências e habilidades básicas exigidas num contexto de reestruturação produtiva, medindo o capital humano disponível em seus territórios. Em outras palavras, o programa busca identificar em que medida os sistemas educativos estão em sintonia com as demandas do mercado de trabalho em um contexto de economias globalizadas. Para a Organização:

O desafio não é simplesmente continuar ensinando a mesma educação, mas preparar os estudantes para um mundo diferente. A digitalização conectou pessoas, cidades, países e continentes, unindo a maioria da população mundial de maneiras que expandem enormemente nosso potencial individual e coletivo. No entanto, as mesmas forças também tornaram o mundo um lugar mais volátil, mais complexo e incerto. Os processos contínuos de automação e remoção de empregos, particularmente no que se refere a tarefas rotineiras, 
alteraram radicalmente a natureza do trabalho e da vida. (OCDE, 2018, p.12, tradução nossa).

Nessa perspectiva, o Capital Humano ocupará a centralidade nos processos de crescimento econômico baseado na ideia da Sociedade do Conhecimento. Se o objetivo geral é fazer com que os estudantes adquiram conhecimentos básicos nos sistemas educacionais e de que as competências sejam a "moeda global do século XXI” (OCDE, 2013), torna-se imperativo não só verificar em quais territórios já se encontram terrenos férteis para mão de obra exigida pelo mercado de trabalho global, mas também identificar quais se aproximam e quais medidas precisam ser tomadas para que possam se tornar nichos de investimentos globais.

Além de verificar com os resultados do Pisa, a OCDE propõe políticas educacionais que têm como objetivo adaptar os sistemas educativos às exigências colocadas. Assim, o programa é instrumento de um projeto maior que busca imprimir ao redor do mundo sistemas educacionais que sejam, apenas, a antessala para o mercado de trabalho. Em um contexto onde exige-se um tipo de trabalhador resiliente, flexível e polivalente, a função social da educação e da escola passa a ser a de formar "cidadãos" práticos, aptos para resolução de problemas exigidos em um mundo que passa por constantes transformações.

Trata-se, portanto, de preparar trabalhadores e consumidores para os novos estilos de consumo e de vida moderna. O cidadão eficiente e competente, nessa ótica, é aquele capaz de consumir de maneira eficiente e sofisticada e de competir com seus talentos, com suas habilidades e com suas competências no mercado de trabalho (OLIVEIRA, 2013, p. 241, grifos do autor).

Em 2015, da América Latina, participaram do Pisa: Argentina, Brasil, Chile, Colômbia, Costa Rica, República Dominicana, México, Peru e Uruguai. A análise dos resultados foi divulgada em 2018 no contexto dos países Ibero-americanos que, além dos enunciados, agregou Portugal e Espanha. Não obstante, o principal documento analisado para este artigo contém inúmeras recomendações direcionadas, prioritariamente, para o contexto latino-americano. A partir da problematização anunciada buscamos analisar quais as estratégias educacionais propostas pela OCDE para a região.

Para perquirir este objetivo o artigo está dividido em duas seções além desta introdução e da conclusão. Na primeira seção buscamos discutir os conceitos de capital humano e sociedade do conhecimento tal como aparecem nos documentos da OCDE; na segunda seção elucidamos as proposições da Organização para educação na América Latina. Passemos à reflexão. 


\section{Capital humano e sociedade do conhecimento: conceitos centrais para OCDE}

Nas publicações da OCDE tem sido recorrente a utilização do conceito de capital humano. Expõe-se que o crescimento econômico está intimamente ligado aos êxitos educacionais a serem alcançados pelos países. Segundo a OCDE,

[...] o capital humano é amplamente definido como algo que abrange uma mistura de talentos e habilidades individuais inatos, bem como as competências e as aprendizagens adquiridas pela educação e pela capacitação [...], o mundo dos negócios tende a defini-lo de modo mais estrito, considerando-o, sobretudo, como as competências e os talentos numa força de trabalho, que estão diretamente vinculados ao sucesso de uma empresa ou indústria. (OCDE, 2007, p. 2, tradução nossa)

Ainda para a OCDE (2007), o capital humano traz inúmeros retornos econômicos e não econômicos, como a melhoria da saúde, maior expectativa de vida e aumento das relações sociais, além de contribuir para um processo de coesão social. Para o Organismo, o aumento da importância do capital humano se dá no bojo do processo de reestruturação produtiva que migra do setor de indústrias para o setor de serviços e demanda um novo tipo de trabalhador, que possa se adaptar às rápidas mudanças inerentes a um processo de transformação globalizada que se renova e se reinventa a passos largos.

Esse processo de reestruturação e transformação global incluiu, na atuação política dos organismos internacionais, o conceito da sociedade do conhecimento. Tal sociedade seria aquela na qual não mais existem relação e contradição de classes. Ou seja, o trabalho e o capital, com as mudanças impulsionadas pelas novas tecnologias de informação e comunicação e no padrão de desenvolvimento da economia, não mais se contradizem, pelo contrário, o capital passa a ser, nesse caso, o humano, elemento principal para acessar o trabalho. Nessa ideologia de sociedade também não há mais a divisão social do trabalho, que consiste na divisão entre trabalho manual e trabalho intelectual. O capital humano constitui-se pela valorização dos conhecimentos e competências a serem adquiridos pelos trabalhadores ao longo de suas vidas. Para a OCDE (2007, p. 1, tradução nossa):

A capacidade dos indivíduos e dos países em se beneficiar dessa economia do conhecimento emergente depende, em grande parte, do seu capital humano sua educação, suas competências, seus talentos e suas capacidades. Disso resulta que o Governo está cada vez mais envolvido no aumento dos níveis do capital humano. Uma das mais importantes maneiras pelas quais o Governo pode fazer isto, é através da educação e da formação, que hoje são vistos como fatores dos mais importantes na contribuição para o crescimento econômico. 
Baseada nessa concepção, a Organização defende que o mais importante é que se necessita de pessoas com as habilidades e competências para fazer com que aumente o capital humano e ele se transforme em crescimento econômico (OCDE, 2016). Dessa forma, a OCDE direciona à educação uma de suas principais estratégias políticas de atuação, entendendo-a como um instrumento para formar mão de obra adequada ao processo de reestruturação do capital, que tem por ideologia subjacente a sociedade do conhecimento.

A educação e as competências reforçam o crescimento econômico, a inclusão social e a força das instituições. Numa economia global baseada no conhecimento, um investimento adequado em capital humano constitui um componente cada vez mais relevante de qualquer estratégia de integração do crescimento. Sem investimento suficiente na aquisição de competências, novas tecnologias e processos de produção são adotados mais lentamente e não se traduzem em novos modelos de crescimento com atividades de maior valor agregado [...]. A única maneira de sair de condições econômicas adversas é o crescimento e, a longo prazo, isso depende mais do que qualquer coisa em fornecer mais pessoas com melhores habilidades para colaborar, competir e se conectar de forma a impulsionar nossas sociedades, e usar essas competências de forma produtiva (OCDE, 2018, p. 32, tradução nossa).

Há uma refinada conexão entre educação e crescimento econômico, mediada pela ideologia da Sociedade do Conhecimento. Tal constructo demanda do indivíduo as destrezas necessárias para colaborar, competir e se conectar em um complexo arcabouço de um mercado de trabalho onde não há vagas para todos e, como consequência, apenas aqueles "com os conhecimentos, as competências, e as qualidades de personalidade adequados" (OCDE, 2018, p. 12, tradução nossa) terão facilidades de se inserirem; por outro lado, "aqueles que padecem de uma preparação insuficiente podem enfrentar as cargas de um trabalho vulnerável e inseguro e de uma vida sem perspectivas" (idem).

Há no discurso da Organização dois elementos básicos: o primeiro de caráter mais amplo que remete a um viés redentor da educação como alavanca para o crescimento econômico dos países, desvinculado de questões estruturais da própria organização econômica das nações; o segundo, de caráter mais restrito, remete ao individualismo como valor moral radical no qual são os indivíduos os responsáveis pelo seu sucesso ou fracasso econômico e social. Neste sentido, indagamo-nos sobre o contexto histórico e as razões que fizeram emergir a crença na sociedade do conhecimento, e também sobre as relações que possui com a concepção de educação da OCDE.

As teorias da sociedade do conhecimento, e/ou economia do conhecimento, estão embasadas na compreensão de que o capital humano se conforma como a chave para o desenvolvimento econômico e social de um país. Esse capital humano é constituído de 
habilidades e competências dos indivíduos que são adquiridas por meio da aprendizagem ao longo da vida. Nesse sentido:

É essencial que se promova o amplo acesso à educação de qualidade e ao treinamento profissionalizante, para aumentar a coesão social e fomentar o crescimento da produtividade agregada do trabalho. O desenvolvimento das habilidades de jovens e adultos, preparando-os para o aprendizado contínuo, portanto, deve ser uma prioridade (OCDE, 2016, p. 6)

Para levar a cabo essa ideologia, os Organismos Internacionais utilizam os governos dos Estados-Nação e os mercados para difundir as bases da sociedade do conhecimento, em busca de transformar a educação em um bem comercializável e de ajustar os trabalhadores "aos imperativos da economia, reconvertida em aprendizagem de 'habilidades economicamente valorizáveis' ou em ‘qualificações para o crescimento econômico"” (LIMA, 2010, p. 42), ou seja, às demandas do processo de reestruturação do capital.

A sociedade do conhecimento constitui-se como ideologia por meio de um processo que inverte as origens das desigualdades sociais e as coloca no bojo da formação individual, desconsiderando, intencionalmente, as determinações econômicas e as relações sociais oriundas do processo constituinte do desenvolvimento do capital que geram as desigualdades. Para isso, seus defensores afirmam "que os debates teóricos sobre os princípios e concepções de educação estão hoje ultrapassados, em função dos grandes consensos estabelecidos” (LIMA, 2010, p.42) no âmbito do capital e dos organismos internacionais. Segundo a OCDE os educadores sofrem de um dilema:

Um dilema para os educadores é que o tipo de coisas que são fáceis de ensinar e verificar são precisamente aquelas que também são fáceis de digitalizar e automatizar. Uma análise mais detalhada dos dados do PISA para os países ibero-americanos mostra que essa é uma das maiores deficiências em seus sistemas escolares. Os alunos são muito mais fortes em tarefas que exigem a reprodução de conteúdo teórico do que naqueles que envolvem processos complexos de resolução de problemas (OCDE, 2018, p. 13, tradução nossa).

Combinando competências e habilidades, a OCDE compõe um processo de verificação dos sistemas educativos, atuando, ao mesmo tempo, como ator e objeto da sociedade do conhecimento, ao induzir o tipo de conhecimento que deve ser produzido para os mercados e o tipo de educação que os governos devem priorizar e para quê.

O período de acumulação flexível que desembocou da crise do capital a partir da década dos anos de 1970 demandou um novo tipo de trabalhador, capaz de se adaptar aos novos padrões de acumulação, transformando-se em um trabalhador polivalente, prontamente qualificado a desenvolver múltiplas tarefas no ambiente de trabalho (FRIGOTTO, 1995). 
Desta forma, a chamada sociedade do conhecimento é uma manifestação ideológica do processo de reestruturação do capital após os anos 1970, produto de uma sociedade de classes em permanente transformação e padronização, sob a égide do processo de internacionalização do capital (FRIGOTTO, 1995; DUARTE, 2008).

Essas transformações, ao longo dos tempos, ressignificaram o conceito da teoria do capital humano (GENTILI, 2005). Um dos pressupostos básicos dessa teoria era que, à medida que aumenta o capital humano, aumenta também a coesão social. Paradoxalmente, a conjuntura aberta nos anos 1980 e, mais profundamente, nos anos 1990, com a ascensão do modelo neoliberal de Estados-Nações, fortaleceu a cultura do individualismo como valor moral radical, da competitividade e da busca pela ascensão particular no mercado de trabalho.

Consoante a isso, a escola púbica passou de centro integrador da coesão social a um centro de desenvolvimento de competências e habilidades específicas e individualizadas que, supostamente, permitissem ao trabalhador conquistar um espaço no mercado de trabalho. Um mercado que exige novas e diversificadas funções dos trabalhadores, assumindo características empresariais. E a educação pública, que era sinônimo de acesso ao emprego para ascensão social, passou a ser espaço de disputa para colocação no concorrido mercado de trabalho (PARO, 1999).

A ênfase nas habilidades e competências individuais foi utilizada pela ideologia da sociedade do conhecimento "como álibi para a falta de ascensão social (e desemprego estrutural). Alega-se, nesse particular, que os egressos da escola não estão preparados para conseguir emprego" (PARO, 1999, p. 10). Além disso, como componente ideológico, inverte a realidade, pois, nesse contexto, "supõe que a escola possa criar os empregos que o sistema produtivo, por conta da crise do capitalismo, não consegue criar" (idem).

A pedagogia das competências é fruto do processo de ressignificação da teoria do capital humano e do abandono da promessa do caráter integrador da escola. "A desintegração da promessa integradora deixará lugar à difusão de uma nova promessa, agora sim, de caráter estritamente privado: a promessa da empregabilidade" (GENTILI, 2005, p. 51).

Na sociedade do conhecimento, a divisão social do trabalho é estimulada pelo nível de instrução, habilidades e competências que cada um tem. Neste particular, a função da escola pública é adquirir funcionamento semelhante ao de empresas, medir a produtividade dos alunos, por meio dos testes e exames, selecionar e divulgar os empregáveis.

$\mathrm{Na}$ acumulação flexível do padrão toyotista de gestão da produção, a pedagogia das competências, do aprender a aprender, sintetiza "uma concepção educacional voltada para a 
formação, nos indivíduos, da disposição para uma constante e infatigável adaptação à sociedade regida pelo capital" (DUARTE, 2008, p. 11).

A pedagogia das competências, como expressão da mudança do padrão de acumulação do capital e da gestão de procedimentos rígidos para procedimentos flexíveis, passou a exigir o desenvolvimento de habilidades cognitivas como: análise, síntese, estabelecimento de relações, rapidez em respostas, criatividade diante de situações desconhecidas, comunicação precisa, interpretação e uso de diferentes formas de linguagem, capacidade para trabalhar em grupo, gerenciar processos, eleger prioridades, criticar respostas, avaliar procedimentos, resistir a pressões, enfrentar mudanças permanentes, aliar raciocínio lógico-formal à intuição criadora, estudar continuamente, entre outras (KUENZER, 2005).

Contudo, possuir habilidades e competências significa ter condições de empregabilidade, não direito ao trabalho. Significa simplesmente ter as melhores condições de competição pelos poucos empregos disponíveis (GENTILI, 2005). E é essa realidade que é ofuscada no emaranhando dos resultados do Pisa que acabam por servir a um processo de desqualificação dos sistemas públicos de educação e de suas finalidades sociais, sobretudo, na desvalorização dos estudantes, docentes e da própria escola.

\section{A política de competências e habilidades para América Latina}

No interior da complexa forma de atuação da OCDE ela dedica atenção especial para os países e regiões considerados em desenvolvimento. Recorrente ao discurso de cooperação técnica e ajuda mútua, a Organização se apresenta como possuidora de soluções inovadoras para as economias mundiais e toma como exemplo aquilo que chama de políticas eficazes de seus países membros como modelos a serem adotados por países que queiram integrar a rota do crescimento econômico e da prosperidade.

Para isso ela realiza diversas atividades, programas, acordos e protocolos com países membros e não-membros com o intuito de difundir as melhores práticas. Os instrumentos que ganham relevo nesse processo são o de "revisão por pares" e "pressão por pares". O primeiro consiste em diagnosticar o conjunto de políticas do país, avaliando-as e identificando o conjunto de problemas sob a ótica da Organização que, a partir daí, propõe recomendações a serem seguidas. O segundo parte do diagnóstico para pressionar os países a implementar as recomendações. 
A pressão também se materializa de variadas formas, sobretudo por meio das publicações sobre os países e regiões. Assim, como parte de uma engrenagem social, as análises representam interesses de governos, setores empresarias e sociais que, em última instância, disputam determinados projetos societários e são portadores de concepções educacionais ligadas aos intentos do capital.

Desde de 2016 a OCDE tem um programa regional para América Latina. Lançado sob a justificativa de que a região se encontra em um ponto de inflexão e que "o contexto macroeconômico atual está pondo a prova o progresso socioeconômico do passado" (OCDE, 2017, p. 6), o programa apresenta como objetivo a urgência de "reformas estruturais encaminhadas para elevar a produtividade, potencializar a integração social e fortalecer a capacidade e a governança do setor público para assim sustentar o desenvolvimento econômico e social" (idem).

$\mathrm{Na}$ ocasião de lançamento do programa ${ }^{2}$, a OCDE lançou um pequeno documento da "série melhores políticas" intitulado: Fomentando o crescimento inclusivo da produtividade na América Latina (OCDE, 2016), onde identificou duas grandes lacunas na região: i) o nível de produtividade dos trabalhadores e, ii) a desigualdade social, e apresentou uma série de recomendações para "apoiar a região a enfrentar este desafio, identificando as prioridades de reformas em seis áreas-chaves de políticas: capital humano, mercado de trabalho, ambiente de negócios, inovação, infraestrutura e governança pública" (OCDE, 2016, p. 1). Portanto, antes mesmo do programa ser lançado a Organização já expressava uma política delineada para a região, que no campo da educação deveria perseguir a melhoria da base de capital humano a partir de recomendações chaves, que seriam:

Construir capacitações mais fortes e mais adequadas por meio do sistema educacional e formação de adultos, com especial atenção para as famílias de baixa renda; Aumentar o investimento em educação, melhorar a infraestrutura das escolas e a qualidade do tempo de instrução; Promover procedimentos de recrutamento e avaliação de professores rigorosos e transparentes, tornando a carreira atraente com mecanismos de progressão; Adotar medidas educacionais eficientes de custo nas salas de aula e de melhor feedback do diretor da escola para os professores; Fortalecer os vínculos entre a educação, a formação e o mercado de trabalho; Avaliar e prever a demanda por qualificações, assegurando que essa informação se traduzirá em políticas destinadas à redução da incompatibilidade de habilidades ou escassez de capacitação (OCDE, 2016, p. 7)

2 O programa é dirigido por um grupo de trabalho que é composto pelos membros da OCDE na região (Chile e México) e pelos "sócios" da América Latina (Argentina, Brasil, Colômbia, Costa Rica, República Dominicana, El Salvador, Guatemala, Panamá, Paraguai, Peru e Uruguai). Chile e Peru coordenam o grupo. 
Esse conjunto programático para a educação Latino-Americana parte do diagnóstico que, embora o acesso à educação na região tenha sido ampliado, seus países ainda apresentam baixo desempenho nas provas do Pisa, o que, segundo a OCDE, não corresponde ao "nível básico de habilidade para ter bom desempenho no mercado de trabalho" (OCDE, 2016, p. 6).

Com a materialização do programa a OCDE passa a analisar de forma mais detida as áreas de políticas públicas expressas nas prioridades elencadas para a região. No campo educacional, a partir dos resultados do Pisa, a Organização publicou o documento: “Competências em Iberoamérica: Analises do Pisa 2015” (OCDE, 2018). A publicação apresenta um conjunto de recomendações que podem ser divididas em três dimensões para/sobre: alunos, escolas (professores e diretores) e sistemas, retomando os pontos elencados quando do lançamento do programa e apresentando novas recomendações.

Desde seu editorial a tônica remete aos conceitos, anteriormente tratados, do capital humano e da sociedade do conhecimento. A ideia central consiste em "preparar os alunos para seu futuro, não para o passado”, preparar os alunos para um mundo diferente.

Para fins de exposição trabalharemos com os pontos levantados no excerto que trouxemos sobre o documento de 2016, cotejando seus elementos com as proposições que emergem no documento de 2018.

- Construir capacitações mais fortes e mais adequadas por meio do sistema educacional e formação de adultos, com especial atenção para as famílias de baixa renda

No documento analisado há o reconhecimento que as desigualdades socioeconômicas entre os estudantes incidem nos resultados da aprendizagem. Além disso, a análise aponta que escolas em territórios periféricos tendem a apresentar níveis mais baixos de desempenho. Defende que em certa medida alunos e escolas de ambientes desfavorecidos possam receber ajuda adicional a partir de "apoios focalizados", contudo, regulada pelos objetivos prescritos e ancoradas no desempenho de competências. Porém, o que mais chama atenção é a relativização da própria proposta e a responsabilização das escolas, professores e diretores acerca da superação dos problemas.

Às vezes, o menor desempenho desses centros pode ser devido menos à extração socioeconômica de seus alunos e mais à resposta inadequada dos centros às necessidades dos alunos, apoio insuficiente ao pessoal (ou a incapacidade da escola de atrair funcionários de qualidade) ou má gestão e prática profissional (OCDE, 2018, p. 168, tradução nossa). 
Nesse sentido a Organização reforça os pressupostos que dão base aos princípios da Nova Gestão Pública. Ou seja, os serviços públicos não dão conta de atender as demandas por conta da inércia e da má formação dos servidores, nesse caso, dos professores; por sua vez, a gestão do setor público é ineficiente e ineficaz, e a prática docente é deficiente por se "limitar" à teoria e não alimentar as competências práticas e instrumentais exigidas pelo mercado de trabalho.

- Aumentar o investimento em educação, melhorar a infraestrutura das escolas e a qualidade do tempo de instrução;

O documento atesta que os países da América Latina investem menos em educação do que a média dos países membros da OCDE, e defende que os países "necessitam de um nível adequado de gasto em educação para proporcionar aos alunos uma educação de qualidade" (OCDE, 2018, p. 110, tradução nossa). Porém, mais uma vez, relativiza a questão ao afirmar que países com níveis parecidos de investimento alcançam melhor rendimento mesmo investindo abaixo da média, o que "indica que pode existir margem para melhorar a eficiência do gasto em educação nos países latino-americanos" (idem, p. 112).

$\mathrm{Na}$ defesa da focalização de gastos para atingir resultados mensuráveis, o documento advoga que "os governos de toda região precisam proporcionar recursos suficientes, ao mesmo tempo que priorizam as dotações financeiras em lugares que possam atingir maior impacto" (idem, p. 158).

Tais proposições acabam por incentivar certa fragmentação do sistema de financiamento público da educação e abre brechas para diferenciação entre escolas, lançando uma verdadeira cruzada por resultados, dissociados da capacidade intelectual do conhecimento, a fim de obter maior impacto para ter disponíveis maiores possibilidades de acesso aos recursos, incentivando competições entre escolas e justificando políticas de ajustes e diferenciação financeira entre as instituições. Por fim, o documento destaca a iniciativa portuguesa de reorganização de sua rede escolar, na qual apresentou-se a possibilidade de fechamento de escolas com baixo rendimento.

- Promover procedimentos de recrutamento e avaliação de professores rigorosos e transparentes, tornando a carreira atraente com mecanismos de progressão;

Segundo o documento, os diretores escolares expõem que, sobretudo em escolas localizadas em territórios menos favorecidos, faltam professores de qualidade. Para resolução deste problema a Organização propõe políticas para carreira docente que consistem em oferecer melhores salários e mecanismos de progressão a fim de tornar a profissão mais atrativa. Advoga 
que tais políticas devem estar vinculadas a mecanismos rigorosos de avaliação e certificação que possam controlar os docentes e medir se estão "transformando os alunos em alunos para vida" e se "eles mesmos aprendem e se desenvolvem ao longo de suas carreiras" (OCDE, 2018, p. 133). Na mesma lógica, defende mecanismos de "incentivo para recompensar o desempenho dos professores" (OCDE, 2016, p. 7).

A solução apresentada aos professores na aparência parece dialogar com as reivindicações das entidades representativas dos docentes que anseiam pela valorização da categoria, contudo, os excertos nos autorizam a inferir que tais medidas estariam condicionadas a uma espécie de Termo de Ajuste de Condutas, ou melhor, nos dizeres da OCDE, "um marco formal de padrões profissionais que orientem a prática docente" (OCDE, 2018, p.183), no qual os professores abrem mão de sua autonomia político-pedagógica e passam a seguir as determinações da concepção de educação defendida pela Organização centrada na aquisição das competências e habilidades e atingindo os resultados almejados.

- Adotar medidas educacionais eficientes de custo nas salas de aula e de melhor feedback do diretor da escola para os professores;

Para além de criticar o excessivo número de alunos em sala por professor, o documento de 2018 não aprofunda o que seriam as "medidas educacionais eficientes de custo nas salas de aula". Ao abordar o papel dos diretores escolares o documento apresenta um conjunto de tarefas que vão desde a coordenação da formação continuada dos professores até a definição de ações para a comunidade escolar, neste sentido, reforça-se a ideia de hierarquia por meio da liderança escolar em detrimento de uma gestão colegiada das instituições.

Uma liderança escolar forte requer a criação do ambiente certo para ajudar os professores a ensinar efetivamente e os alunos a aprenderem bem. Consequentemente, os diretores de escolas não são apenas responsáveis por gerenciar seu funcionamento e administração, mas também definem as atitudes, motivação e comportamento da comunidade escolar para continuar melhorando. No nível do sistema, a liderança é essencial para contribuir para a implementação adequada das políticas de educação, já que as escolas são a frente de batalha do desempenho. (OCDE, 2018, p. 180, tradução nossa, grifo nosso).

\section{- Fortalecer os vínculos entre a educação, a formação e o mercado de trabalho}

De acordo com o documento, "muitos dos desafios econômicos e sociais enfrentados pela região ibero-americana, como baixa produtividade, falta de integração social e alta taxa de 
desemprego entre os jovens, podem estar diretamente ligados à baixa qualidade da educação e ao desenvolvimento limitado de competências" (OCDE, 2018, p. 33, tradução nossa).

Para enfrentar tais desafios a Organização sugere a adoção da formação profissional ligada às demandas do mercado de trabalho. Nesse sentido, "os sistemas educativos deveriam se reformar para atender as necessidades dos alunos e as mudanças requisitadas pelo mercado de trabalho, por exemplo, oferecendo opções de formação para quem desejar entrar direto no dito mercado" (idem, p. 166). O documento aponta que os alunos de programas integrados de educação secundária e profissional obtiveram melhor desempenho, porém, chama a atenção a afirmativa que:

Isto pode indicar que muitos sistemas de educação e formação profissional na região são, de fato, muito exigentes e prestigiosos e têm um maior foco acadêmico. Este modelo pode desencorajar os alunos com menos aspirações acadêmicas e que podem ser atraídos por formas mais práticas de aprendizagem (OCDE, 2018, p. 167).

Revela-se então que não basta vencer a batalha do desempenho, é preciso ainda verificar se ele se coaduna com as características mais práticas do mercado. Neste sentido, a contradição é aguçada, pois pergunta-se: se o Pisa mede as competências e habilidades requeridas para o mercado e, se os programas de formação que integram educação secundária e profissional, propiciam aos alunos melhores rendimentos, qual seria o problema do "maior enfoque acadêmico"?

Nos parece que a lógica das competências e habilidades, ao contrário do que parece ser, em sua essência estimula a criação de trabalhadores flexíveis, adaptados à nova dinâmica de produção do capital, transformando-os em cumpridores de múltiplas tarefas instrumentais, sem ligação com o "domínio intelectual da técnica” (KUENZER, 2005).

- Avaliar e prever a demanda por qualificações, assegurando que essa informação se traduzirá em políticas destinadas à redução da incompatibilidade de habilidades ou escassez de capacitação

A OCDE tem como suposto que a incompatibilidade dos sistemas educativos de menor desempenho no Pisa se dá por conta da ineficiência da aquisição de competências e habilidades para o mercado de trabalho. Nessa toada defende que os governos devem definir uma matriz de competências com as "partes interessadas" no sucesso educacional. Assim advoga que,

[...] para que as escolas sejam empreendedoras e capazes de se adaptarem, os que dirigem os sistemas devem ser capazes de mobilizar os recursos humanos, sociais e financeiros necessários para inovação; atuar como empreendedores sociais dentro e fora de suas próprias organizações; e estabelecer vínculos 
mais sólidos entre os setores e os países, com a finalidade de estabelecer alianças com as autoridades públicas, os empreendedores sociais, os executivos empresarias, os investigadores e a sociedade civil (OCDE, 2018, p. 19, tradução nossa).

Uma das estratégias da Organização tem se consolidado por meio do conceito de Governança Pública. A Governança tem como pressuposto a ideia de que os governos não são mais capazes de governar e que é preciso "democratizar a democracia" ampliando a participação de setores da sociedade na definição e execução das políticas públicas. Nesse percurso se sobressaem os setores privados, que passam não só a definir quais são as prioridades dos sistemas educacionais, assim como seu conteúdo e a formação dos professores, mas também a execução de políticas. Pois bem, nos parece que a indicação de avaliar e prever as qualificações necessárias tem como pressuposto colocar no centro das decisões acerca dos sistemas públicos atores privados e seus interesses imediatos, em detrimento dos interesses públicos e sociais do percurso educativo.

\section{Considerações finais}

Neste artigo buscamos analisar algumas das proposições da OCDE para América Latina. Para atingir o objetivo discutimos os conceitos centrais que sustentam o Pisa e as recomendações que faz a Organização a partir dos resultados do programa.

Ao considerar o Capital Humano como elemento chave para o crescimento econômico, a OCDE difunde a ideologia da Sociedade do Conhecimento como um contexto político, econômico e social que exige a ampliação de competências e habilidades dos sujeitos para que estes tenham condições de empregabilidade em um mercado onde não há espaço para todos.

Nesse percurso, utilizando o Pisa e seus resultados como instrumento de sua concepção tecnicista de educação a fim de padronização dos sistemas educativos, propõe uma série de medidas para os estudantes, professores, diretores e escolas. Tais medidas partem de um diagnóstico que reforça a ideia de que os serviços públicos são ineficientes, no caso da educação, por não ofertarem as competências e habilidades demandadas por um mercado de trabalho em constante transformação.

Para a América Latina, independente das características de formação econômica e social da região e dos países, propõe um conjunto de medidas que tem como centralidade a retomada do crescimento econômico sob os pressupostos das estratégias do novo ciclo de produção e reprodução do capital em nível global. 
As proposições que constam dos documentos analisados versam sobre políticas que acentuam a dualidade estrutural da educação; a focalização de recursos em detrimento de uma visão universal e unitária dos sistemas educativos; um novo tipo de regulação transnacional do trabalho docente; aprofundamento dos processos de verificação em larga escala; intensificação do trabalho dos diretores e centralização das decisões e iniciativas; acento na formação para o mercado de trabalho dissociada da formação intelectual e integral dos estudantes; participação dos setores empresariais na definição e execução das políticas educacionais.

Esse conjunto programático para a educação na América Latina acaba por dissociar a formação dos estudantes de um leque mais amplo de conhecimentos que possibilite acesso a um arcabouço emancipador, que eleve o pensamento crítico e social buscando a compreensão e formulação de conhecimentos alternativos que contribuam para superar as extremas desigualdades sociais que permeiam a região latino-americana.

\section{REFERÊNCIAS}

DUARTE, Newton. Sociedade do conhecimento ou sociedade das ilusões? Quatro ensaios crítico-dialéticos em filosofia da educação. Campinas, SP: Autores Associados, 2008.

FRIGOTTO, Gaudêncio. Educação e a crise do capitalismo real. São Paulo, Cortez, 1995.

GENTILI, Pablo. Três teses sobre a relação trabalho e educação em tempos neoliberais. In: LOMBARDI, José Claudinei; SAVIANI, Demerval; SANFELICE, José Luís (Orgs.). Capitalismo, trabalho e educação. $3^{\circ} \mathrm{ed}$. Campinas, SP: Autores Associados, HISTEDBR, 2005.

KUENZER. A.Z. Inclusão excludente e Exclusão includente. In: LOMBARDI, José Claudinei; SAVIANI, Demerval; SANFELICE, José Luís (Orgs.). Capitalismo, trabalho e educação. $3^{\circ} \mathrm{ed}$. Campinas, SP: Autores Associados, HISTEDBR, 2005.

LIMA, Licínio C. A Educação faz tudo? Crítica ao pedagogismo na "sociedade da aprendizagem”. Revista Lusófona de Educação, n.15, p. 41-54. 2010.

OCDE. Capital humano: Cómo influye en su vida lo que usted sabe. Publicações OCDE. 2007.

OCDE. Melhores competências, melhores empregos, melhores condições de vida: Uma abordagem estratégica das políticas de competências. Publicações da OCDE, 2013.

OCDE. Fomentando o crescimento inclusivo da produtividade na América Latina.

Publicações da OCDE, 2016.

OCDE. Activos con América Latina y el Caribe. Publicações da OCDE, 2017. 
OCDE. Competencias en Iberoamérica: Análisis de PISA 2015. Fundación Santillana, 2018.

\section{Como referenciar este artigo}

PEREIRA, R. S. Proposições da OCDE para América Latina: O PISA como instrumento de padronização da educação. Revista Ibero-Americana de Estudos em Educação, Araraquara, v. 14, n. esp. 3, p. 1717-1732, out., 2019. e-ISSN: 1982-5587. DOI: 10.21723/riaee.v14iesp.3.12756

Submetido em: 25/03/2019

Revisões requeridas: 20/04/2019

Aceito em: 20/07/2019

Publicado em: 30/08/2019 